\title{
Urban aerobiological risk mapping of ornamental trees using a new index based on LiDAR and Kriging: A case study of plane trees
}

\author{
Raúl Pecero-Casimiro \\ Universidad de Extremadura \\ Santiago Fernández-Rodríguez \\ Universidad de Extremadura \\ Rafael Tormo-Molina \\ Universidad de Extremadura \\ Follow this and additional works at: https://arrow.tudublin.ie/scschcpsart
}

Part of the Allergy and Immunology Commons, Biochemistry, Biophysics, and Structural Biology Eeenextpage for additionahauthors mmental Health and Protection Commons, and the Other Forestry and Forest Sciences Commons

\section{Recommended Citation}

Raúl Pecero-Casimiro, Santiago Fernández-Rodríguez, Rafael Tormo-Molina, Alejandro Monroy-Colín, Inmaculada Silva-Palacios, Juan Pedro Cortés-Pérez, Ángela Gonzalo-Garijo, José María Maya-Manzano, Urban aerobiological risk mapping of ornamental trees using a new index based on LiDAR and Kriging: A case study of plane trees, Science of The Total Environment, Volume 693, 2019, 133576, ISSN 0048-9697, DOI: 10.1016/j.scitotenv.2019.07.382.

This Article is brought to you for free and open access by the School of Chemical and Pharmaceutical Sciences at ARROW@TU Dublin. It has been accepted for inclusion in Articles by an authorized administrator of ARROW@TU Dublin. For more information, please contact arrow.admin@tudublin.ie, aisling.coyne@tudublin.ie, gerard.connolly@tudublin.ie.

Funder: Regional Government, Junta de Extremadura (Spain); the European Regional Development Fund; Irish Environmental Protection Agency (EPA)

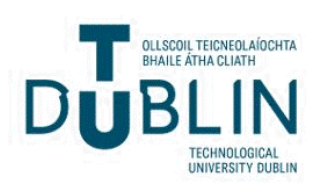




\section{Authors}

Raúl Pecero-Casimiro, Santiago Fernández-Rodríguez, Rafael Tormo-Molina, Alejandro Monroy-Colín, Inmaculada Silva-Palacios, Juan Pedro Cortés-Pérez, Ángela Gonzalo-Garijo, and J. M. Maya-Manzano 


\title{
Urban aerobiological risk mapping of ornamental trees using a new index based on LiDAR and Kriging: A case study of plane trees
}

\author{
Raúl Pecero-Casimiro a , Santiago Fernández-Rodríguez ${ }^{\mathrm{b}}$, Rafael Tormo-Molina ${ }^{\mathrm{a}}$, \\ Alejandro Monroy-Colín ${ }^{\mathrm{a}}$, Inmaculada Silva-Palacios ${ }^{\mathrm{c}}$, Juan Pedro Cortés-Pérez ${ }^{\mathrm{b}}$, \\ Ángela Gonzalo-Garijo ${ }^{\mathrm{d}}$, José María Maya-Manzano ${ }^{\mathrm{e}, *}$ \\ a Department of Plant Biology, Ecology and Earth Sciences, Faculty of Science, University of Extremadura, Avda. Elvas s/n, Badajoz, Spain \\ ${ }^{\mathrm{b}}$ Department of Construction, School of Technology, University of Extremadura, Avda. de la Universidad s/n, Cáceres, Spain \\ ${ }^{c}$ Department of Applied Physics, Engineering Agricultural School, University of Extremadura. Avda. Adolfo Suárez s/n, Badajoz. Spain \\ ${ }^{\mathrm{d}}$ Department of Allergology, University Hospital Complex Badajoz. Avda. Elvas s/n, Badajoz, Spain \\ e School of Chemical and Pharmaceutical Sciences, Technological University Dublin, Kevin Street, D08 X622, Dublin, Ireland
}

\section{H I G H L I G H T S}

- An Aerobiological Index studying the risk provoked by ornamental trees is proposed.

- AIROT uses LiDAR data to consider not only biological but also geographical factors.

- It enables mapping risks in different cities according to their own characteristics.

- Healthy itineraries for allergic patients are proposed by using risk mapping.

- AIROT is an efficient tool in urban planning and a way to assess plane tree's risk.

\section{A R T I C L E I N F O}

\section{Article history:}

Received 8 February 2019

Received in revised form 19 July 2019

Accepted 22 July 2019

Available online 25 July 2019

Editor: Elena Paoletti

\section{Keywords:}

Aerobiological index

Healthy urban itineraries

Kriging

Plane trees and allergies

LiDAR

Urban planning

\section{G R A P H I C A L A B S T R A C T}

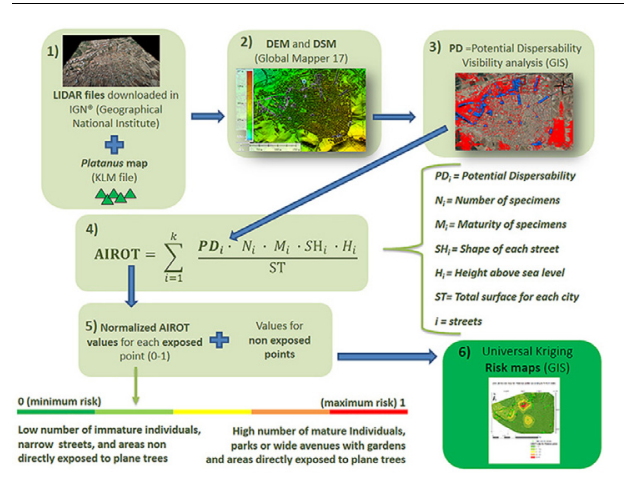

\begin{abstract}
A B S T R A C T
Ornamental trees bring benefits for human health, including reducing urban pollution. However, some species, such as plane trees (Platanus sp.), produce allergenic pollen. Consequently, urban maps are a valuable tool for allergic patients and allergists, but they often fail to include variables that contribute to the "building downwash effect", such as the width and shape of streets and the height of buildings. Other factors that directly influence pollen dispersion (slopes and other geographical features) also have not traditionally been discussed. The LiDAR (Laser Imaging Detection and Ranging) technique enables one to consider these variables with high accuracy. This work proposes an Aerobiological Index to create Risk maps for Ornamental Trees (AIROT) and the establishment of potential areas of risk of exposure to Platanus pollen.

LiDAR data from five urban areas were used to create the DEM and DSM (Digital Elevation and Surface Models) needed to perform further analysis. GIS software was used to map the points for each city and to create risk maps by Kriging, with stable ( 3 cases) and exponential function ( 2 cases) as the optimal models. In short, the AIROT index was a useful tool to map possible biological risks in cities. Since AIROT allows each city to consider its own characteristics, including geographical specifications, by using remote sensing and geostatistics techniques, the establishment of risk maps and healthy itineraries is valuable for allergic patients, allergists, architects and urban planners. This new
\end{abstract}

\footnotetext{
${ }^{*}$ Corresponding author.

E-mail addresses: raulpc@unex.es (R. Pecero-Casimiro), santiferro@unex.es (S. Fernández-Rodríguez), ratormo@unex.es (R. Tormo-Molina),bioamc@outlook.com (A. Monroy-Colín), insilva@unex.es (I. Silva-Palacios), jpcortes@unex.es (J.P. Cortés-Pérez), magonzalog@gmail.com (Á. Gonzalo-Garijo), jose.manzano@dit.ie (J.M. Maya-Manzano).
} 
aerobiological index provides a new decision-making tool related to urban planning and allergenicity assessment.

\section{Introduction}

Currently, world overpopulation has become a significant problem that exacerbates pollution and urban air quality deterioration problems. In $2010,73 \%$ of European citizens lived in urban areas, and this number is predicted to increase to $>80 \%$ by 2050 , with associated problems of traffic, air pollution, safety and noise (Comission-Mobility, 2017). Aerobiological information is being considered as an element of design in green infrastructure planning, potentially avoiding the entrance of pollen into these areas (Fernández-Rodríguez et al., 2018). Thus, the evaluation of local factors and mapping the sources (Rohde and Muller, 2015) can be used to enhance air quality. Urban maps are increasingly being produced with multiple applications, including land-cover features, residential heat and health impacts (Jenerette et al., 2016), monitoring the invasion of natural landscapes by urban trees (Gavier-Pizarro et al., 2012) and urban flowering maps (Massetti et al., 2015).

There is recent scientific interest in urban green aspects and their potential to contribute positively to human health (Ekkel and de Vries, 2017), including landscape ecological urbanism (Steiner, 2011). Urban forests contribute immensely to the sustainability of cities and public health (Coutts, 2016), with trees considered by some as indispensable (Duinker et al., 2015). Certainly, their presence can succeed in mitigating the urban heat island effect (Maimaitiyiming et al., 2014). We need to begin to consider the need to produce future urban planning scenarios, based not only on aesthetic criteria regarding the urban landscape but also to benefit the evaluation of suitable trees in view of their potential for allergenicity (Cariñanos et al., 2017).

Platanus sp. is included amongst the most allergenic ornamental trees used in urban planning (Fernández-González et al., 2013a) but is widely used in Mediterranean urban environments (Maya-Manzano et al., 2017a) due to its low price, rapid growth, wide shadow and tolerance to water shortages. Furthermore, its popularity could be related to irrigation management and extension in peri-urban landscapes (Maheshwari and Plunkett, 2015). Blanusa et al. (2015) indicated that Platanus planting could be considered in Mediterranean urban environments due to its efficiency in accumulating and retaining airborne particles. We consider it appropriate to begin this work with plane trees due to both their importance and allergenicity. Moreover, the mapping for these trees was done in previous studies for the same region as the current work (Maya-Manzano et al., 2017a; Maya-Manzano et al., 2017c), and the capability of dispersion is limited (Bricchi et al., 2000), which implies that this tree could be appropriate.

Aerobiological source mapping in a territory is an interesting topic due to the importance of vegetation for airborne content (Maya-Manzano et al., 2017b; Rojo et al., 2015; Smith et al., 2008) and consequently for human health. Lately, the knowledge gaps about the influence of ornamental plants in the pollen spectrum inside cities are being filled (Cariñanos et al., 2014; Maya-Manzano et al., 2017a; Maya-Manzano et al., 2017c; Staffolani et al., 2011; Velasco-Jiménez et al., 2014). However, it is not as common that those that have studied this topic have added maps to determine the influence of source locations within a city and in urban green infrastructures (Fernández-Rodríguez et al., 2014a; Maya-Manzano et al., 2017a). In fact, the use of these maps in practical decision tools has been often overlooked. Therefore, their influence on the population, especially allergic patients, allergists and policy makers, needs further study.

In urban assessment and planning criteria, the use of remote sensing (Senes et al., 2016) and, in particular, LiDAR (Light Detection and Ranging or Laser Imaging Detection and Ranging) is becoming increasingly widespread. In recent years, LiDAR has been used to analyse bioaerosols in rural environments (Luo et al., 2017) and in urban ecosystems (Chen et al., 2017) to estimate biomass. Other uses related to urban planning include the assessment of urban tree condition (Plowright et al., 2016), their mapping (Alonzo et al., 2014; Dian et al., 2016), prediction of tree species richness (Gillespie et al., 2016), studies in conifer phenology (Lin and West, 2016), quantification of the 3D structure of vegetation (including height) (Caynes et al., 2016; Imai et al., 2004), and urban tree canopy cover (Lovasi et al., 2013; Parmehr et al., 2016). Furthermore, M. Sicard et al. (2016); P. Sicard et al. (2016) studied pollen grains by near-surface and columnar measurements and with diurnal patterns of their vertical distribution (Noh et al., 2013).

We suggest that LiDAR could be useful for mapping possible biological risks in cities, considering some factors that are critical for understanding the dispersion process for pollen grains in cities, such as geographical slopes and features and the influence of buildings and other barriers within cities, which contribute to the building downwash effect (Thompson, 1993). The width of the streets and heights of the buildings can potentially lead to high concentrations of particles in some places (Cariñanos et al., 2002), and they can be considered an effective barrier in other cases. Some authors have included topography and geography in the mapping of pollen sources and pollen dispersion (Puppi Branzi and Zanotti, 1992), but the inclusion of this topic together with urban barriers remains a gap in the literature.

Another important geostatistical tool frequently used for creating risk maps is Kriging, a well-known interpolation method that has been widely used in diverse scientific disciplines, including the environmental sciences. Amongst them, we can cite its inclusion in phenological studies (León-Ruiz et al., 2011; León Ruiz et al., 2012) or, in a way similar to our proposed work, as a function composed of some independent environmental variables such as altitude, slope, urbanisation, and geographical features (Puppi and Zanotti, 1989). Kriging has also been used in other disciplines such as crop productivity (Machida et al., 2012) and maps of vegetation inventories and biomass calculations (Tsui et al., 2013). It is especially important in countries with vast surfaces occupied by tropical rainforests (Fayad et al., 2015). In regards to air pollution, Kriging was used to create urban risk maps of environmental pollution (Berens et al., 2017; Matějíček et al., 2006; Rohde and Muller, 2015; P. Sicard et al., 2016). Finally, regarding aerobiological studies, Kriging has been used for estimating pollen concentrations in middle points lacking available samples (Alba et al., 2006; Della Valle et al., 2012; Oteros et al., 2019) and for establishing comparisons between the flowering of plants and airborne pollen concentrations (Rojo and Pérez-Badia, 2015).

Recent publications describe the creation and use of indexes in aerobiology, such as the work of Fernández-González et al. (2013b), Mrđan et al. (2017) and Ríos et al. (2016). In urban planning, aerobiological indexes have been created based on the allergenicity in urban parks (Cariñanos and Casares-Porcel, 2011; Cariñanos et al., 2017). For this, the composition of the flora and some biological and developmental characteristics of trees present in several Spanish parks were studied. Using some parameters (some of them not usually seen in the aerobiological literature) for creating a new aerobiological index for all urban scenarios, together with a combination of LiDAR and Kriging, would enable the creation of risk maps for dispersion. We assume that some of these geographical features influence biological factors, decreasing the pollen concentration with the height (Gehrig and Peeters, 2000) and bringing forward the pollen release when specimens are more exposed to sun radiation than those in the shade (Kjelgren and Clark, 1992), because the heat requirement for pollen release would be achieved earlier. These factors could lead to a higher exposure in populations within these areas. In 
the same way, if pollen has difficulty dispersing to some places because of obstacles, there would be the same difficulty in dispersion from these same areas. It could be used as a novel and powerful tool for mapping urban healthy itineraries for the population (Maya-Manzano et al., 2017a), giving information about the most harmful places for allergic patients and being a useful tool for allergists. Our study considered several urban elements that have ornamental plane trees planted in an integral way to establish different zones of urban risk to said pollen type. Ornamental tree species have been used to assess the particulate matter exposure in urban environments (Barima et al., 2014), and Platanus spp. is one of the main urban ornamental trees with allergenic potential in the Mediterranean region (Fernández-González et al., 2013a), with high potential for allergenicity (Cariñanos et al., 2017).

This work aims to establish one additional step to the method described in a previous publication (Maya-Manzano et al., 2017a) and to use the available information regarding the geolocation of plane trees in five cities of Extremadura (SW Iberian Peninsula), combined with available and free-to-use LiDAR data (IGN, 2019) to accomplish the primary goals.

1) To propose an Aerobiological Index to create Risk maps for Ornamental Trees (hereafter, AIROT), that takes into account different parameters that influence this risk. For this analysis, we use wellknown aerobiological parameters (abundance of pollen sources and maturity degree of specimens), together with aspects that seem to play unclear roles in aerobiology, such as geographical features, slopes, height above the sea level and intrinsic differences in the urban characteristics for each city, including the presence of buildings and differences in urban planning.

2) Based on LiDAR data, and considering the AIROT index and the geolocation of the ornamental trees, to create risk maps for plane trees by using Kriging in each city. Points with high and low risks of exposure will be established, which will be valuable for creating urban healthy itineraries (taking as an example the city of Badajoz) or identifying comfortable points.

\section{Materials and methods}

\subsection{Sampling site}

Extremadura (Fig. 1) is a large region $\left(41,635 \mathrm{~km}^{2}\right)$ located in the SW Iberian Peninsula (Europe) that is sparsely populated $(1,072,863$ inhabitants according to NSI, 2017, a density of 26 inhabitants $/ \mathrm{km}^{2}$ ). Its surface is mostly dedicated to agriculture and extensive farming, with natural landscapes dominated by holm and cork oaks (Quercus rotundifolia and Q. suber) and pastures in the south, and Pyrenean oaks ( $Q$. pyrenaica) and chestnuts (Castanea sativa) in the north. Other species, such as pines (Pinus pinea and P. pinaster) and eucalyptus (Eucalyptus camaldulensis, E. globulus) were widely planted for silviculture and have naturalized. Regarding its orography, this region is crossed by two main rivers (Guadiana and Tajo) separated by a central medium-high mountain range that runs along the two provinces, Badajoz and Cáceres, with $290 \mathrm{~km}$ from the northern border to the southern. Its climate is characterized by mild winters and hot summers, with a continental Mediterranean climate and an annual mean temperature of $16.7^{\circ} \mathrm{C}$ with an annual rainfall of $499 \mathrm{~mm}$ (AEMET, 2018).

The cities in Badajoz province in this study were Badajoz (BA) $\left(38^{\circ} 53^{\prime}\right.$ $\mathrm{N}, 6^{\circ} 58^{\prime} \mathrm{W}, 184$ m.a.s.l.), Don Benito (DB) ( $38^{\circ} 58^{\prime} \mathrm{N}, 5^{\circ} 50^{\prime} \mathrm{W}, 253$ m.a.s. 1.), both with flat orography in their surroundings, and Zafra (ZA) $\left(38^{\circ} 25^{\prime}\right.$ $\mathrm{N}, 6^{\circ} 25^{\prime} \mathrm{W}, 508$ m.a.s.l.), with the mountain range of La Alconera in the west of the city. In the Cáceres province, we studied Cáceres (CC) $\left(39^{\circ} 48^{\prime}\right.$ $\mathrm{N}, 6^{\circ} 20^{\prime} \mathrm{W}, 459$ m.a.s.l.) and Plasencia (PL) $\left(43^{\circ} 10^{\prime} \mathrm{N}, 2^{\circ} 25^{\prime} \mathrm{W}, 253\right.$ m.a.s. 1.), the first one with the mountain range of Fuentes dividing the city in two, and the second one located in the valley floor of the Jerte river. The importance, location and number of individual plane trees in these five

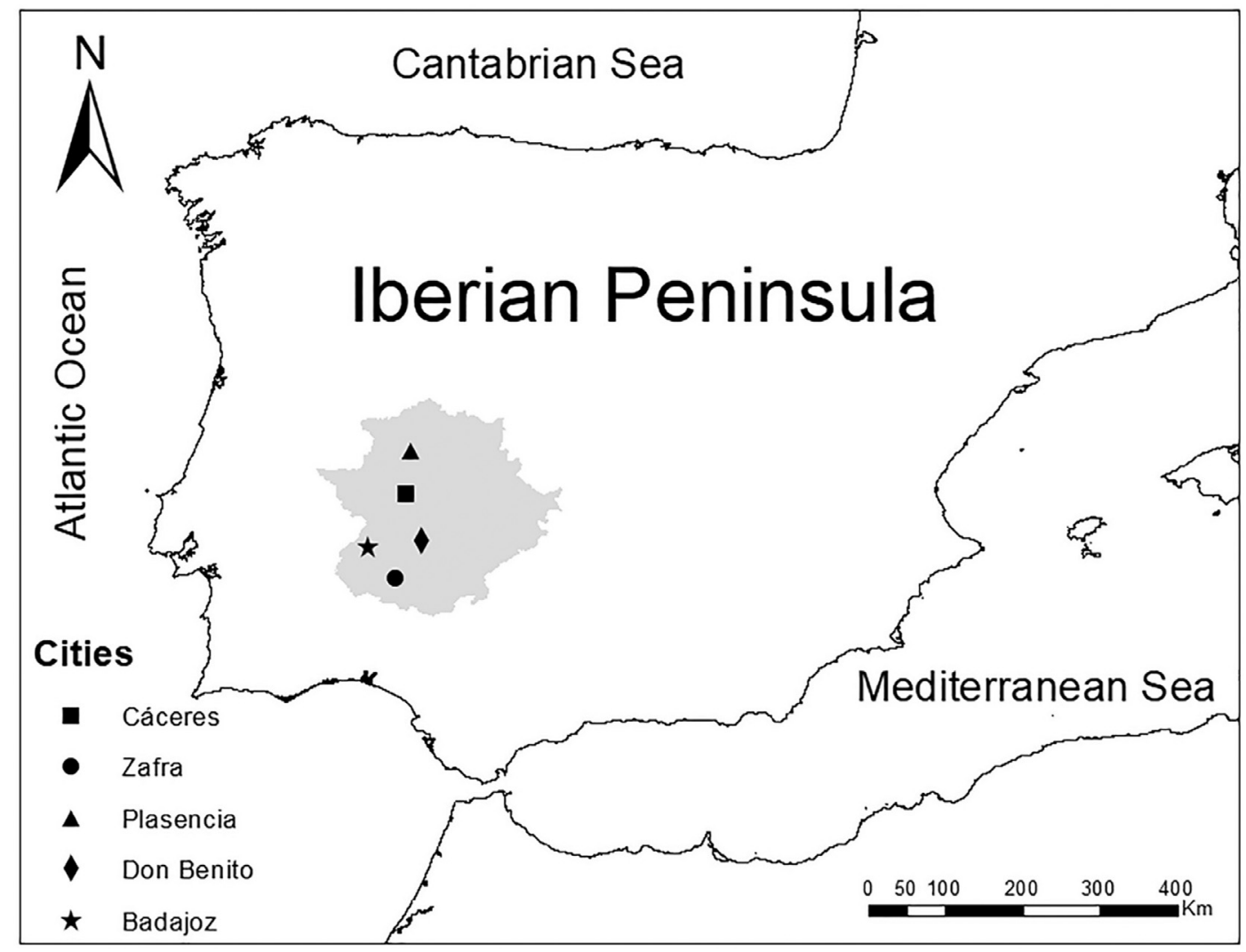

Fig. 1. Map of Extremadura in the Iberian Peninsula and the location of the studied cities. 
cities were previously studied (Maya-Manzano et al., 2017a), with the annual average concentrations for three of these cities of 15.1 (DB), 1.7 (PL) and $1.2(\mathrm{ZA})$ pollen grains $\mathrm{m}^{-3}$ and being the second (after Olea europaea), the first and the second (after Ulmus minor) ornamental trees in importance for the same three cities (Maya-Manzano et al., 2017c). Their surface ranged from 15.4 and $13.6 \mathrm{~km}^{2}$ for BA and CC to $4.8,4.3$ and $3.5 \mathrm{~km}^{2}$ for PL, DB and ZA. For BA and CC, the predominant urbanisation type is mainly medium-high buildings for the new residential areas, with wide boulevards or avenues and some large parks and squares, together with narrow streets for the historical streets in the city centre. In the rest of the cities, which are smaller than these two, the most abundant urbanisation type is narrow streets with residential units of one or two floors for each household. Some parks with abundant plane trees are located in more open spaces. The most important areas for Platanus pollen risk according to the calculated index can be consulted in the supplementary material section (Table S1).

\subsection{LiDAR data}

Groups of $2 \times 2 \mathrm{~km}$ LiDAR images for each urban area (dated in 2010, the only database available to date for this region) were used to create the DEM (Digital Elevation Model) and DMS (Digital Surface Model) needed to perform the visibility analysis in the following steps (used in AIROT as Potential Dispersability). They have a LiDAR density point cloud of 0.5 points $/ \mathrm{m}^{3}$ and were obtained from the website of the Instituto Geográfico Nacional ${ }^{\circledR}$ (IGN, 2019) in LAS files. These files present some anomalous points (misclassifications, incoherent points according their heights, etc.) that need to be removed from all locations to avoid mistakes in the following steps. The software package Global Mapper 16.2 (Blue Marble Geographics, 2016) was used, and DEM and DSM in raster were created with the same computer programme. LiDAR technology is very helpful in the construction of these digital models, for considering all of the buildings, trees and other possible obstacles or barriers in the creation of DSM with high accuracy and excellent resolution, and above all the shape characterization of each building (Gamba and Houshmand, 2000). Fig. 2 shows some LiDAR point clouds for different sites, paying attention to buildings and vegetation.

\subsection{Creation of the index of risk for ornamental trees. A case study: plane trees}

Since the Aerobiological Index of Risk for Ornamental Trees (AIROT) was proposed using the same parameters and numerical range for a city, it allows for the establishment of comparisons of the risk of pollen exposure from ornamental trees (plane trees) amongst cities and even areas within the same city (Fernández-Rodríguez et al., 2013; Maya-Manzano et al., 2017a). In each street, average values for each parameter were taken into account, and when differences between parameters were found, we considered as many points as necessary, with the goal of being as representative as possible responding to the observed changes. These different sampling points in the vegetation characteristics within each street were particularly necessary in some main avenues and parks, due to their large size. A detailed work scheme is shown in Fig. 3.

The index is proposed considering the physical (places where trees are located, shape of street, elevation and slopes obtained from the LiDAR database, because they determine the potential of dispersion for pollen grains) and biological (maturity degree and number of specimens) features of each ornamental tree and the characteristics of the urban street design. Combinations of these parameters are proposed by eq. (1), the Aerobiological Index of Risk for Ornamental Trees (AIROT):

AIROT $=\sum_{\mathrm{i}=1}^{\mathrm{n}} \frac{\mathrm{PD}_{\mathrm{i}} \cdot \mathrm{N}_{\mathrm{i}} \cdot \mathrm{M}_{\mathrm{i}} \cdot \mathrm{SH}_{\mathrm{i}} \cdot \mathrm{H}_{\mathrm{i}}}{\mathrm{ST}}$

where
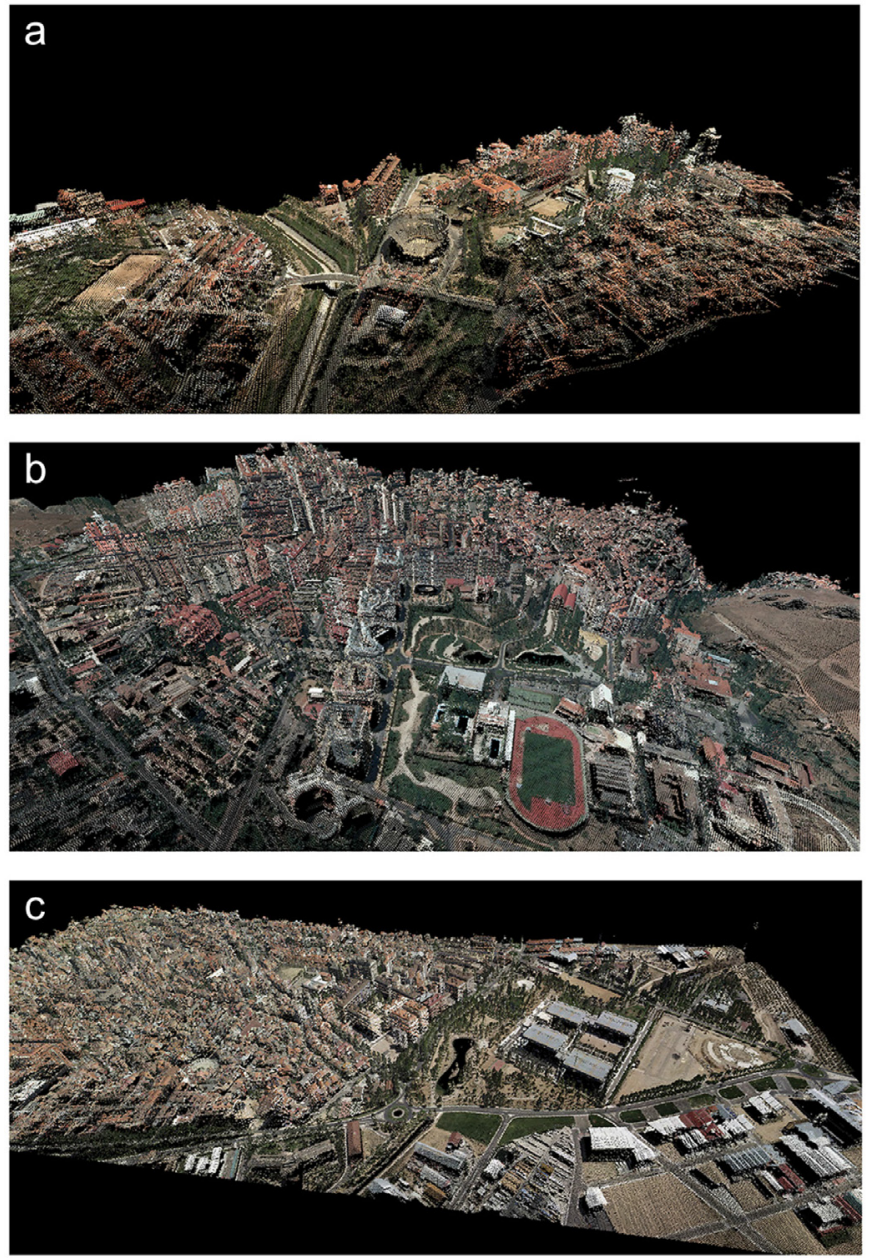

Fig. 2. a. LiDAR point cloud for the city of Badajoz. b. LiDAR point cloud for the city of Cáceres. c. LiDAR point cloud for the city of Don Benito.

$\mathrm{PD}_{\mathrm{i}}=$ Potential Dispersability $(0,10)$;

$\mathrm{N}_{\mathrm{i}}=$ Number of specimens by distance (trees/ha) (from 0 to 10);

$\mathrm{M}_{\mathrm{i}}=$ Maturity degree for each specimen $(1,5,10)$;

$\mathrm{SH}_{\mathrm{i}}=$ Incidence and presence of high buildings, narrow streets and squares $(1,2,4,6,8,10)$;

$\mathrm{H}_{\mathrm{i}}=$ Height above sea level $(1,5)$;

$\mathrm{S}_{\mathrm{T}}=$ total surface of the city in $\mathrm{km}^{2}$;

$\mathrm{i}=$ streets

The calculated index was normalized, taking values between 0 (minimum risk, in green colour) and 1 (maximum risk, in red colour) and mapping each street of each city according to these scores.

The index was created while taking into account the following parameters:

\subsubsection{Potential Dispersability (PD)}

Potential Dispersability modelling establishes the extent to which a nominated feature may be seen from a specified location (Bartie et al., 2011). This parameter was calculated by means of the visibility analysis, which was carried out using commercial GIS software and taking into account all of the buildings and heights presented surrounding the selected points (the plane trees). By using a LiDAR point cloud to create DSM to perform this analysis, high accuracy can be achieved in this digital model, and we can consider all of the possible potential barriers in dispersion. In particular, by means of the tool called "View Shed", with a transmitter elevation of $5 \mathrm{~m}$ height, we 


\section{1)}

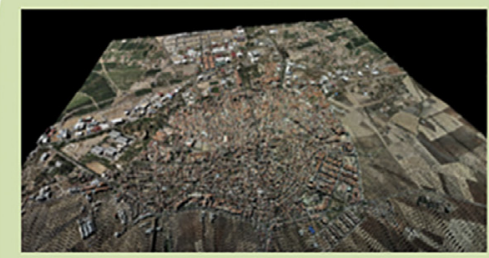

LIDAR files downloaded in IGN ${ }^{\circledR}$

(Geographical National Institute)
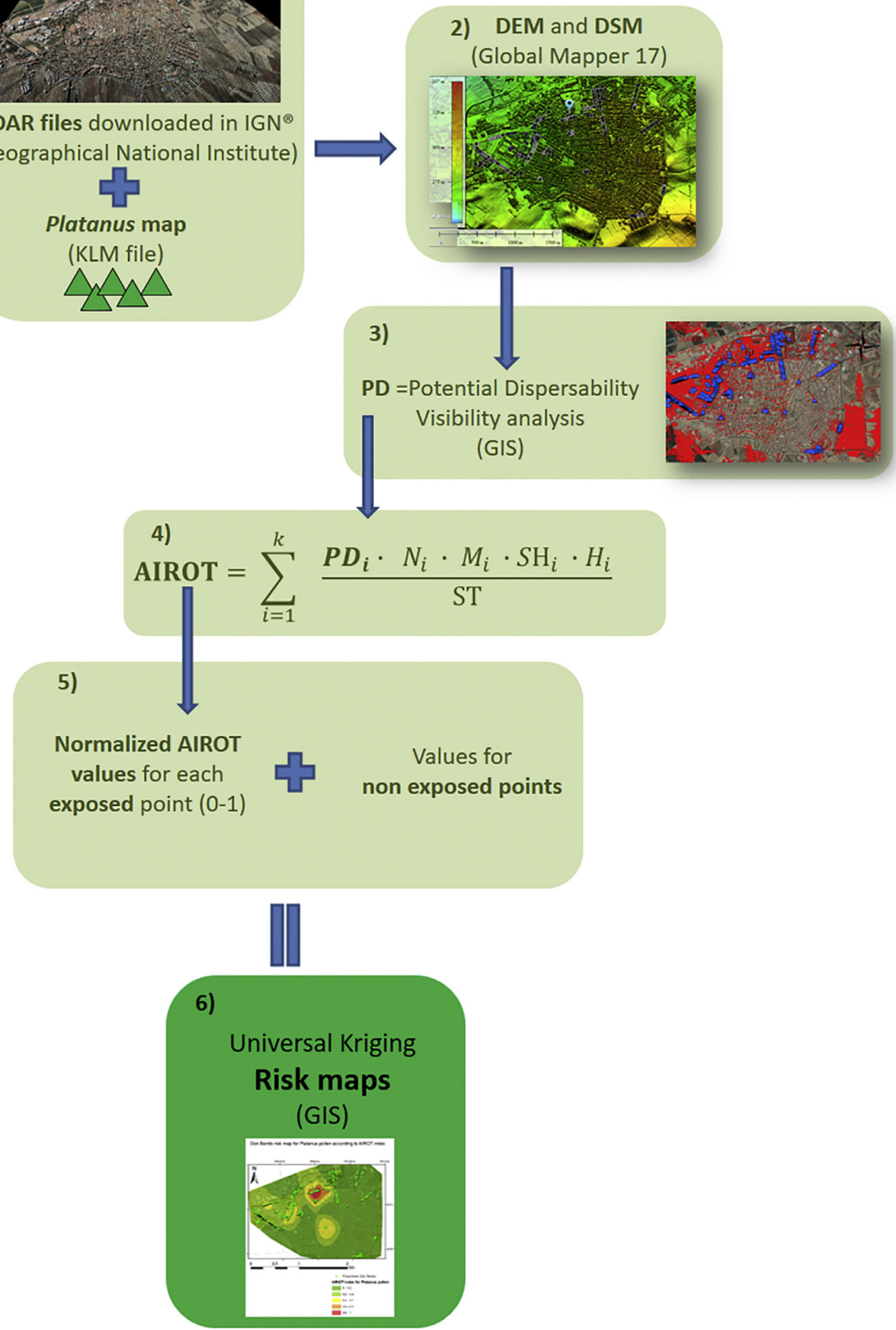

Fig. 3. AIROT work scheme 
considered the trees with a minimum of this size as risky for human health and capable of releasing pollen, increasing their capability of dispersion according to their maturity. According to Skjøth et al., (2013), in the case of birch, pollen will be significantly released in specimens with a height ranging from 5 to $20 \mathrm{~m}$ above the ground. This value has been used to establish control visibility values (Murgoitio et al., 2013). With this size, the trees would not only be located a few metres above the ground and would be able to avoid the lower buildings, but it also takes into account that trees have a minimum maturity degree. The receiver elevation would be any point with $1.5 \mathrm{~m}$ height because it would be an ordinary height for human exposure. This score was given in absolute values, dividing the areas as exposed (10) or not exposed (0). Middle scores were not considered.

\subsubsection{Number of specimens by distance in each street $(N)$}

The presence of sources of vegetation is an important factor that influences the pollen load in one area (Maya-Manzano, 2017b; Rojo and Pérez-Badia, 2015). To be able to compare different cities in future studies, we calculated the density of individuals for each street (trees/ha), and their values were normalized from 0 to 10 , considering the number of individuals studied in Maya-Manzano et al. (2017a).

\subsubsection{Maturity degree for each specimen (M)}

A maturity degree score (trunk diameter and branch development) was given for each street. This parameter has been studied and considered as essential in the potential to release pollen, making it possible to have higher pollen concentrations (Maya-Manzano et al., 2017a). Due to possible differences between the maturity degree amongst the plane trees located in a single street, they were scored as an average, considering a higher value when necessary. This is because in cases when some plane trees are still immature, a conservative score could mask the real risk in the near future. For this reason, according to the three life stages of the tree (Germino et al., 2002; Thomas and Winner, 2002) and the stages of development, we propose these values for plane trees: young (1), from the time when they are planted until the first year in which they can produce flowers, adult (5) and mature (10), for trees $>10$ years old.

\subsubsection{Incidence and presence of high buildings, narrow streets and squares $(\mathrm{SH})$}

Considering the presence of narrow streets and high buildings as a theoretical barrier that handicaps pollen dispersion (Cariñanos et al., 2002), lower scores were given in these streets for this parameter. Based on the classifications of previous papers (Barnett, 2008; Golan, 2015; Hoekstra, 2012; Sreelekha et al., 2017), we proposed these values: local residential/office/commercial/industrial street (1), parkway (2), boulevard (4), main street (6), and wide avenue (8). Regarding parks or public squares (10), a priori they are more suitable to allow tree pollen dispersion because they have large areas of open space and fewer obstacles, allowing a better air flux renewal. This kind of urban microenvironment also allows the correct development of the tree crown, as was reported for Robinia pseudoacacia L. and Tilia cordata Mill. (Bayer et al., 2018).

According to a previous study (Kjelgren and Clark, 1992) of Liquidambar styraciflua L., the individuals in parks and squares received unobstructed sunlight, with thinner leaves and less trunk growth in canyon streets compared with parks.

To distinguish between avenues and wide streets, we proposed to take into account the number of traffic lanes as an easy indicator, with 4 or more considered as avenues. We also consider avenues with parks and those of greater width (more so than wide avenues, 4 traffic lanes plus parking and sidewalks) as parks, in order to consider that dispersion is easier.

\subsubsection{Height above sea level $(H)$}

According to Scheifinger et al. (2002), at a local or regional scale, changes in phenological time series can be induced by micro-meteorological conditions in mountainous areas (20-40 days every $1000 \mathrm{~m}$ of elevation). It is provoked by disturbances in the North Atlantic Oscillation (NAO), which maintains temperature inversions for long periods of time in valleys, causing an increase in time for the different phenophases. The authors grouped the sampled locations into those of height $>1500 \mathrm{~m}$ or height $<1500 \mathrm{~m}$ above sea level. This is consistent with the findings of Sharma et al. (2012), who estimated an average production of pollen cone per tree of $42.44 \pm 8.32 \times 10^{3}$ at lower altitudes and $28.1 \pm 0.89 \times 10^{3}$ at higher altitudes. We propose to use the same two categories previously mentioned in Scheifinger et al. (2002), using values of 1 for higher altitudes (sampling points within the city $>1500$ m.a.s.l) and 5 for lower altitudes (places within the city $<1500$ m.a.s.l). This parameter can be useful to distinguish the behaviour of phenology in places with points in the two categories, or making it possible to compare amongst different places, including different countries and different bioclimatic regions.

However, since the 5 cities studied in this work belong to the second category (all the places in these cities were below 1500 m.a.s.l), this parameter was not relevant in our calculations.

\subsection{Kriging and risk maps}

The Kriging technique is performed by means of complex mathematics, algorithms and equations. This technique gives estimations based on semivariogram calculations about continuous variables at points where there were no monitoring stations or sampling points. Each function is tested until the best fitness to the points is found, according to the values for Root Mean Square Error (RMSE) and the Spearman's rank correlation. The Kriging was carried out using commercial GIS software and the two mentioned parameters by using R statistical software (R-Team, 2013). Five different functions (Stable, Circular, Spherical, Exponential and Gaussian) were compared (Table 2). The semivariograms for the optimal models (Fig. S1), the cross validation for each model and city (Fig. S2), together with the uncertainty maps (Fig. S3), can be found in Supplementary materials. After that, the different points and the coordinate $z$ (AIROT index) were studied by ordinary Kriging, which was used considering the 25 closest values to locate the continuous scores in intermediate areas inside the surfaces studied. According to the AIROT index, raster maps with scores for different streets with plane trees present or not were created for each city. To study the cities, a balance between representativeness for all places and computational resources was taken into account, and samples were taken from 162 (PL) to 680 points (CC) to be as representative of all changes produced in the parameters as possible.

\subsection{Healthy itineraries}

Healthy itineraries for the city of Badajoz, as an example, were created using GIS, taking into account the official transport network for this city; in other words, the network of roads for vehicles and pedestrian areas, downloaded from the website of the Instituto Geográfico Nacional ${ }^{\circledR}$ (IGN, 2019). Two different routes were advised (one from south to north and another from east to west). To plan the best path to be taken by pedestrians, we considered the following points:

- The pedestrians should take a path included in the existing transport network.

- The suggested path should be in areas with the minimum AIROT risks for as long a distance as possible.

- The itinerary should avoid, if possible, the points with high PD or directly exposed points (according to the visibility analysis).

- At moments when it was not possible to accomplish the two previous parameters, the itinerary should minimize the risks, including crossing where the AIROT values are as low as possible or using the most direct route in order to make the path as safe as possible. 


\section{Results}

\subsection{Values for AIROT}

Table 1 shows the average for each parameter considered in AIROT according to the number of sampling points (not the absolute number of trees, but the density). Badajoz and Cáceres had the highest values ( 0.34 and 0.25 ), while Plasencia was estimated as the lowest (0.16). We can see how the highest number of individuals is located in Badajoz and Cáceres; those are also the biggest cities amongst those studied. We can also say that Cáceres and Badajoz generally contained the most mature specimens, present mostly on wide avenues or in parks, where they had grown for several years. Thus, Badajoz recorded the maximum value of the number of specimens (3.23), while Cáceres was remarkable for the maturity of the plane trees (9.96) and the shape of the streets (8.69). The cities of Badajoz and Cáceres are the most exposed because they contain many wide avenues, mostly landscaped areas. All of these things combined gave Badajoz higher values for AIROT. Don Benito showed a maturity of 6.40 and street shape of 5.51, obtaining an AIROT of 0.24 . Zafra did not show any parameters in particular with higher values, but all of them can be considered as medium-high, maturity (6.61) and streets (5.81), which brought the AIROT index higher than Plasencia. Finally, Plasencia had its sampling points in areas with many trees, but they were still immature (3.40). This outcome, added to its lower exposure (narrow streets, residential areas without or with few plane trees, etc.), was reflected in a lower AIROT.

\subsection{Risk maps using LIDAR and Kriging analysis}

The results for the Kriging analysis are shown in Table 2. The Exponential and the Stable functions were the optimal models in all the cities. Stable models frequently produce suitable results because this kind of function takes an additional shape parameter that allows changing curvature in the models while they maintain the nugget, the range and the sill. In Don Benito and Zafra, the Exponential model was the most robust according to Spearman's correlation test and the RMSE. For Cáceres and Badajoz, the Stable model was the winner, and finally, for Plasencia, the Stable and the Gaussian models were similar, although being slightly better the Stable. The highest values for the index (Supplementary material) came from large avenues, squares and parks, where the absence of solid obstacles facilitates dispersion; these areas also generally have a certain number of mature individuals, as in Badajoz and Cáceres (Fig. 4A and B). Badajoz contained three different hotspots, located in the NW, SW and SE. Curiously, according to the followed methodology, the points with more risk to facilitate exposition through the city were large avenues, and some parks (e.g., San Francisco) did not reach the maximum AIROT. Cáceres seems to be divided into two main areas, one in the SW and the other in the SE, with lower values in the middle, which can be explained by the presence of a mountainous geography that crosses the city. The same happened in Don Benito (Fig. 4C). Here, the maximum values were obtained in the north of the city, in areas with more open spaces. In contrast, in the centre and the south of the city, the exposure risk seems to be lower, corresponding with areas with

\section{Table 1}

Average values for the main parameters used in AIROT (please note that it is not the absolute number of specimens, but the density of individuals normalized from 0 to 10 ).

\begin{tabular}{lcccc}
\hline City & $\begin{array}{l}\text { Number of } \\
\text { specimens }(\mathrm{N})\end{array}$ & $\begin{array}{l}\text { Maturity of } \\
\text { specimens }(\mathrm{M})\end{array}$ & $\begin{array}{l}\text { Shape of streets } \\
(\mathrm{SH})\end{array}$ & AIROT \\
\hline Badajoz & 3.23 & 9.87 & 8.45 & 0.34 \\
Caceres & 3.08 & 9.96 & 8.69 & 0.25 \\
Don Benito & 1.86 & 6.40 & 5.51 & 0.23 \\
Plasencia & 3.06 & 3.40 & 3.13 & 0.16 \\
Zafra & 2.17 & 6.61 & 5.83 & 0.19 \\
\hline
\end{tabular}

fewer individuals, with most of them being immature and located in narrow streets due to the age of the neighbourhoods.

Having a large number of plane trees is another factor for increasing the value of AIROT, but not always, as seen in the Plasencia map (Fig. 4D). In this map, despite having some areas with a great number of specimens, most areas belong to the first category in maturity degree, which can be translated into low scores in this parameter. Therefore, some parts of each city have great importance. This could be due to the presence of high density hotspots for large squares and some big parks. This can be observed in the centre-South of Plasencia. Finally, in Zafra (Fig. 4E), due to the concentration of almost all trees in two isolated main spots in the NW and in the city centre, we have a homogeneous distribution of AIROT values, with a characteristic concentric ring shape for these two points.

\subsection{Healthy itinerary}

Fig. 4A shows how an allergic patient can take different paths to avoid the risk of exposure to Platanus pollen within the city of Badajoz. Despite being crossed by plane trees in the south of the city, the safer itinerary includes crossing some main avenues at certain points according to the requirements explained in Section 2.5.

\section{Discussion}

New tools related to 3D simulations, mapping and urban planning in cities are becoming more common, and they are helpful to integrate aerobiology in urban studies. Previous studies of local dispersion of airborne particles such as Pinaceae concentration assessed the meteorological conditions with innovative engineering techniques such as BIM (Building Information Modelling) (Fernández-Rodríguez et al., 2018). The wind direction pattern was considered because the studied area was limited to one delimited and specific area in the city of Badajoz (approximately $150 \mathrm{~m}$ ), and close enough to one meteorological station and the sampling point. However, to consider the meteorology for different points in cities is a complex task, taking into account current limitations, such as the locations of the weather stations, which are usually located outside the cities, as in our case. This leads to a lack in the representativeness of the weather parameters when we want to extrapolate values within the entire city. Thus, the influence of the wind direction patterns has been studied based on the pollen content provided for each wind direction, as it has already been considered in previous studies of the same five cities (Maya-Manzano et al., 2017a) and their surroundings (Fernández-Rodríguez et al., 2014b; Maya-Manzano et al., 2017c). Those studies reported the implications of the predominant wind direction patterns if those were aligned with the main sources of pollen, and how sources located in different directions and their aerobiological contents can be underestimated. The influence of the wind direction considering the location of the sources has also been discussed by Silva-Palacios et al. (2000). Due to the previously described factors, the meteorological influence is beyond the scope of this study. When we introduced the total surface for each city into the equation, we considered the limited dispersion of plane tree pollen (Bricchi et al., 2000), taking into account that the differences in risks and pollen dispersion should be more notable in big cities. The maximum values are achieved when one sample point is composed mostly of a great number of mature individuals, in a park or large avenue with a large area, and is directly exposed to plane trees.

Parks or public squares could show more suitable conditions for the potential dispersion of airborne particles because they allow for a better air flux renewal and the correct development of the tree crown; for example, in a study of Robinia pseudoacacia L. and Tilia cordata Mill. (Bayer et al., 2018). If it is true that they are not the same species, in Maya-Manzano et al. (2017c), the importance of trunk maturity and branch development for Platanus is highlighted. A further study to compare the trunk and branch development and 
Table 2

Results for the different functions that were tested in the Kriging analysis according to the RMSE and the Spearman's rank correlation. Better results coloured in bold.

\begin{tabular}{|c|c|c|c|c|c|}
\hline City/function & Stable & Circular & Spherical & Exponential & Gaussian \\
\hline Badajoz & $\begin{array}{c}\text { RMSE }=0.127 \\
r=0.852\end{array}$ & $\begin{array}{c}\mathrm{RMSE}=0.136 \\
r=0.842\end{array}$ & $\begin{array}{c}\mathrm{RMSE}=0.134 \\
r=0.845\end{array}$ & $\begin{array}{c}\text { RMSE }=0.126 \\
r=0.851\end{array}$ & $\begin{array}{c}\mathrm{RMSE}=0.148 \\
r=0.826\end{array}$ \\
\hline Cáceres & $\begin{array}{c}\text { RMSE }=0.087 \\
r=0.850\end{array}$ & $\begin{array}{c}\mathrm{RMSE}=0.091 \\
r=0.828\end{array}$ & $\begin{array}{c}\mathrm{RMSE}=0.091 \\
r=0.828\end{array}$ & $\begin{array}{c}\text { RMSE }=0.087 \\
r=0.847\end{array}$ & $\begin{array}{c}\text { RMSE }=0.091 \\
r=0.826\end{array}$ \\
\hline Don Benito & $\begin{array}{c}\text { RMSE }=0.176 \\
r=0.765\end{array}$ & $\begin{array}{c}\mathrm{RMSE}=0.167 \\
r=0.775\end{array}$ & $\begin{array}{c}\text { RMSE }=0.164 \\
r=0.779\end{array}$ & $\begin{array}{c}\text { RMSE = 0.151 } \\
r=0.794\end{array}$ & $\begin{array}{c}\mathrm{RMSE}=0.209 \\
r=0.693\end{array}$ \\
\hline Plasencia & $\begin{array}{c}\text { RMSE }=0.108 \\
r=0.697\end{array}$ & $\begin{array}{c}\text { RMSE }=0.118 \\
r=0.662\end{array}$ & $\begin{array}{c}\text { RMSE }=0.117 \\
r=0.668\end{array}$ & $\begin{array}{c}\text { RMSE }=0.121 \\
r=0.662\end{array}$ & $\begin{array}{c}\text { RMSE }=0.108 \\
r=0.697\end{array}$ \\
\hline Zafra & $\begin{array}{c}\text { RMSE }=0.097 \\
r=0.782\end{array}$ & $\begin{array}{c}\mathrm{RMSE}=0.099 \\
r=0.778\end{array}$ & $\begin{array}{c}\text { RMSE }=0.097 \\
r=0782\end{array}$ & $\begin{array}{c}\text { RMSE = 0.103 } \\
r=0.786\end{array}$ & $\begin{array}{c}\text { RMSE }=0.097 \\
r=0.782\end{array}$ \\
\hline
\end{tabular}

consequently pollen production is needed, specifically for those plane trees located in parks and the specimens located in narrow streets.

In this sense, we included the Potential of Dispersability (PD), which is considered as a theoretical indicator of potential pollen dispersion and transport from one place to another. It highlights which areas in each city would have direct exposure to the pollen coming from ornamental trees or from other places and which areas would not (isolated points would not be as risky as open spaces for allergic patients as described in Section 2.3.4.). Minimum values will be recorded in narrow streets, with no plane trees present and no direct exposure to any of them. However, there is no consideration of a null category because the authors consider that a null value can be only theoretical, and the presence of pollen can be provoked by refloating or from other streets near to those studied. The values given in the current work are a first approach. All the parameters must continue to be under study, and the values should be continuously readjusted in future studies. We consider that the source locations (as they are ornamental trees, their presence is restricted to urban locations) and the Potential Dispersability (PD) make it easier to estimate the possible presence of airborne pollen content at specific points for each location, according to the predominant wind directions for each city. Therefore, in BA (Fig. 4A), when the wind blows from the NE, the risk is lower than when blowing from the SW or SE. For CC (Fig. 4B), winds from the SW are potentially dispersing more Platanus pollen than winds from the NW. Finally, in DB, PL and ZA (Fig. 4C, D and E), winds blowing from the N could bring higher pollen concentrations if the rest of the parameters included in AIROT (presence of trees, maturity of specimens, wide streets allowing good wind flow and Potential Dispersability) were appropriate. All these considerations are very useful for cities with planted green infrastructure or to project new green infrastructure urbanism projects.

The visibility analysis, even though it has some limitations (that are shared with atmospheric modelling in a small space within a city), could be a good enough approach to the problem of the concentric effect provoked by turbulence in pollen dispersion, provoked by street canyons. The pollen that will be dispersed by these turbulent movements can be removed from monitoring due to the random effect.

At the least, we can ensure that some points can be more exposed than others based on this tool, which can be interpreted easily. As emission sources, $5 \mathrm{~m}$ was considered as a minimum, because this size was proposed for other trees in the literature (for Betula, Skjøth et al., 2013), and the receptor at $1.5 \mathrm{~m}$ height. Regarding the Kriging analysis, some authors reported optimal results with the same models as the current study (Dindaroğlu, 2014), although other authors found the Gaussian to be more suitable (Oteros et al., 2019).

AIROT is proposed to complement the Index of Urban Green Areas (IUGZA) (Cariñanos et al., 2014), which does not consider meteorological parameters. The index presented here focuses on the geography and the shape of the streets. In addition, unlike IUGZA, it takes into account all areas outside and inside parks. Our study proposed to indicate which areas of each city are the safest from the aerobiological point of view, and which areas have more risk, considering the particularities and characteristics of each city, as was explained in Sections 3.1 and 3.2. Consequently, it is possible to compare AIROT based on an element of urban green infrastructure, namely plane trees, between several cities using a normalized value (0-1). Therefore, it is proposed that AIROT is a scalable index (Cariñanos et al., 2014) that could be implemented in more cities (Cariñanos et al., 2017). Mueller et al. (2018) normalized five scales of values of urban parameters for a city, including road network, $\mathrm{PM}_{2.5}$, noise levels and green space, in order to create a health impact assessment to establish multiple environmental burdens.

A factor to consider is to limit the values for each ornamental tree being studied by using this index. Thus, as an example, for this first approach, we focused on the growth rate of plane trees and their maturity degree; these may be different for each species and even for localities (Vaz Monteiro et al., 2017), which should be noted. Moreover, there are authors that have found a positive relationship between pollen production by trees and the diameter of the tree crown (TormoMolina et al., 1996) or trunk diameter (Maya-Manzano et al., 2017c). Since this factor is associated with each specific tree, to give a representative score for each species regarding the maturity of the individuals can be important to properly apply the index. Due to the difficulties in determining the exact age of each tree, we took into account the age according to observations at different periods by using tools such as Street View in Google Maps, following the same methodology as in previous studies (Maya-Manzano et al., 2017a). Regarding the number of specimens, since the number of specimens and the area occupied by each street are easy to obtain, by using the density of trees (trees/ha), this index can be easily extrapolated and used in other cities, allowing the comparison in multi place studies. The same aim is managed by adding the altitude, making the application of this index at places in different regions easier (for example, in comparisons including risks in cities worldwide).

Modelling carried out using LiDAR offers the opportunity to consider the geographical features involved in the dispersion of the pollen grains. On the basis of previous urban planning studies (Maya-Manzano et al., 2017a; Maya-Manzano et al., 2017c), we feel it is necessary to improve urban mapping in order to use it as a prevention tool in order to design urban healthy itineraries (Fig. 4A). These healthy itineraries show the best path to be taken by allergic patients through a city, to move amongst these paths from distant points by minimizing risks. In this sense, AIROT and the risk maps are proposed as a useful tool. Actually, the capital cities are proposing to reduce contaminants $\left(\mathrm{CO}_{2}\right.$, mainly) in their development plans (Johnson et al., 2017; Tang et al., 2018). This idea is scalable to develop urban models of exposure to urban organic pollutants such as pollen types with allergenic potential. To assess the health impact, the risk and exposure have been analysed as a part of urban and transport planning (Mueller et al., 2018), including the particulate matter distribution of herbaceous and tree leaves (Barima et al., 2014). We consider this idea appropriate to implement with ornamental sources of pollen and the allergenic effect of pollen. These maps are useful to identify areas at risk, as source mapping can be used to enhance air quality (Rohde and Muller, 2015) and to express the phenological response from the impervious surface gradient and seasonal thermal variations (Massetti et al., 2015). Furthermore, dispersion and 
a

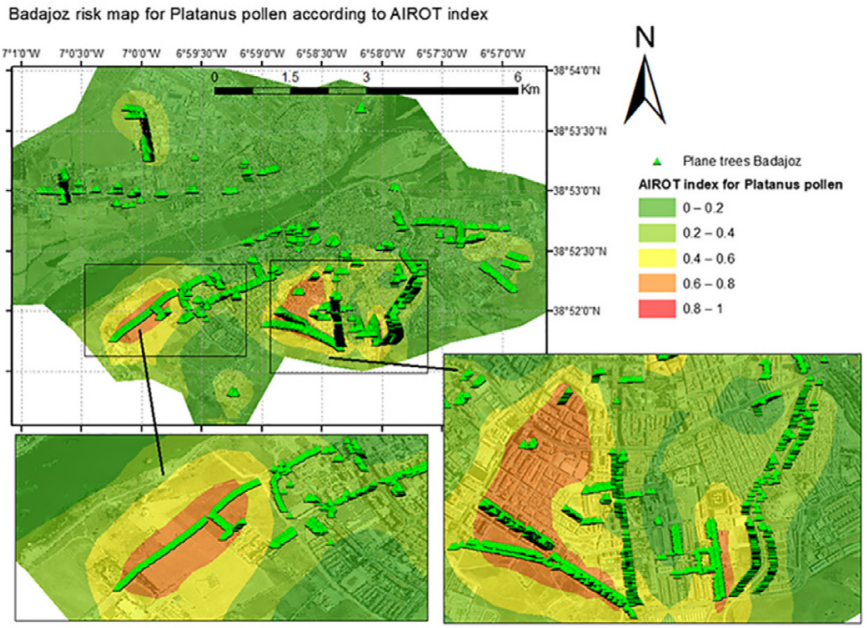

b

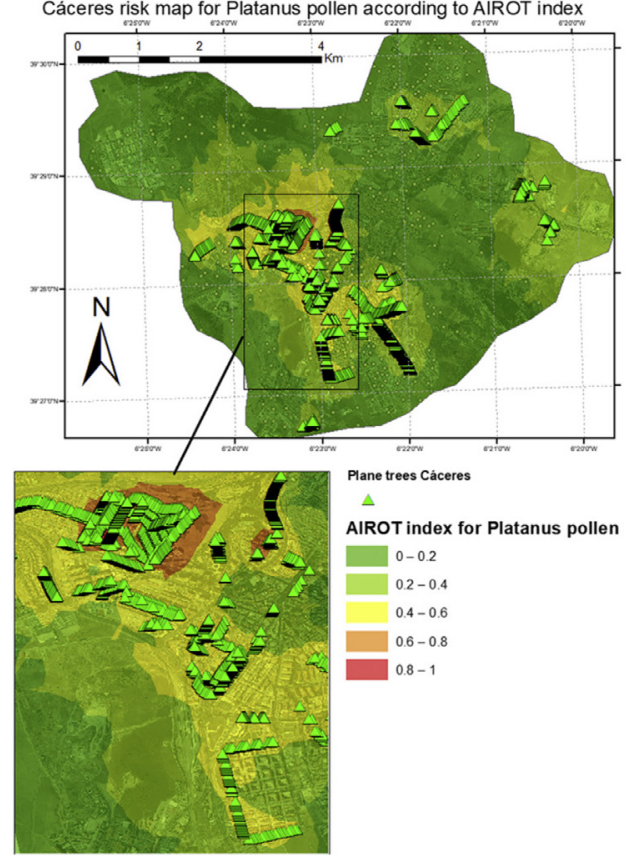

d

Plasencia risk map for Platanus pollen according to AIROT index

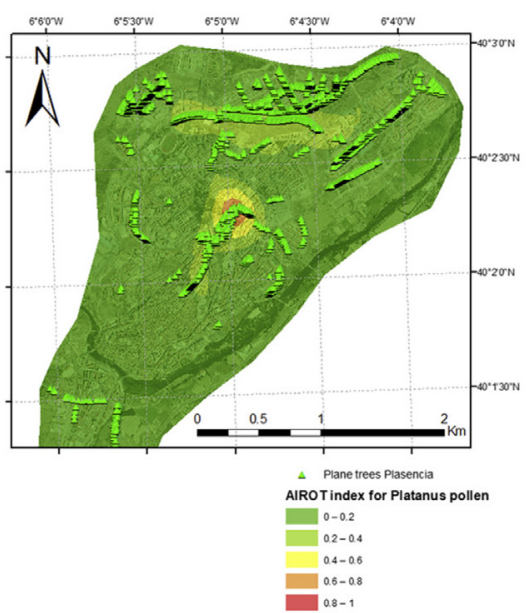

Healthy itinerary for Badajoz

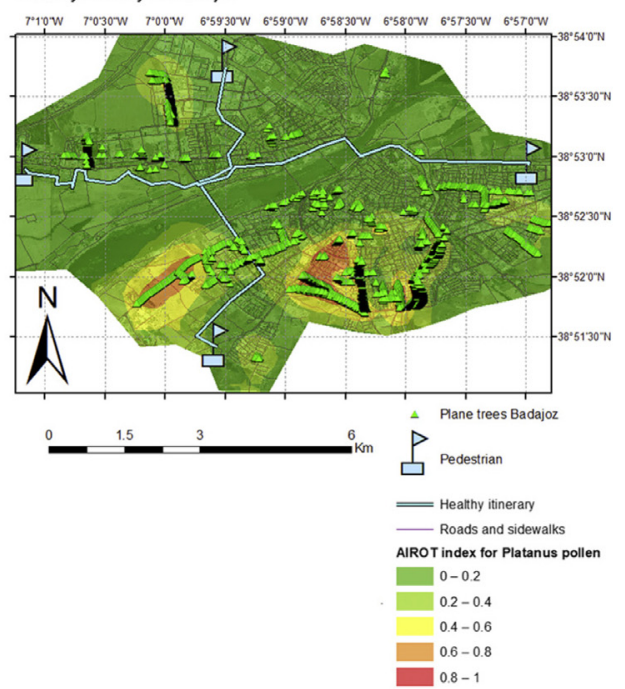

C

Don Benito risk map for Platanus pollen according to AIROT index

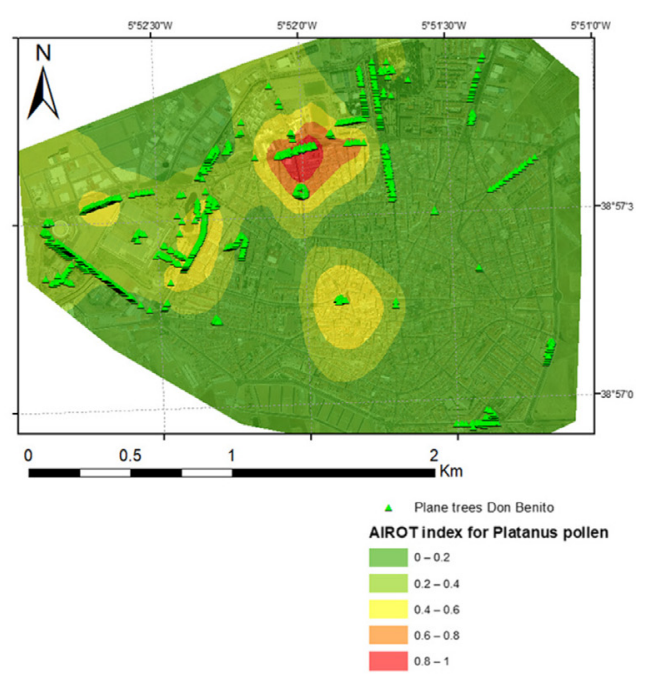

e

Zafra risk map for Platanus pollen according to AIROT index

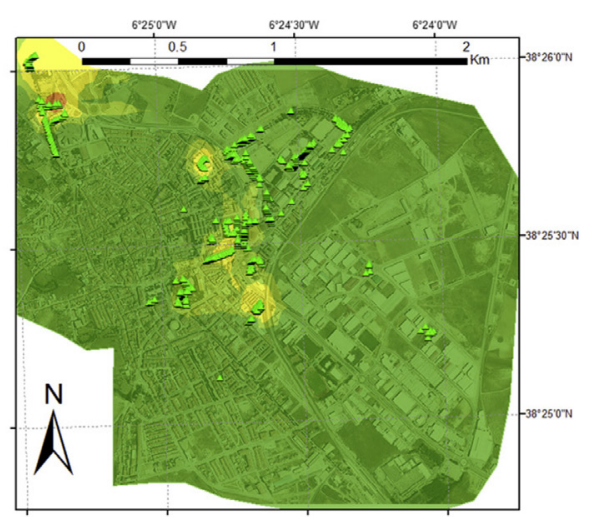

4 Plane trees Zatra

AIROT index for Platanus pollen

$0-0.2$

$04-0.0$

- $0.0-0.8$

Fig. 4. Risk maps for each city according to the AIROT index (4A Badajoz and Health itinerary example, 4B Cáceres, 4C Don Benito, 4D Plasencia, 4E Zafra). 
exposure have been considered in urban planning with other aims, such as roadside vegetation barrier designs to mitigate near-road air pollution impacts (Tong et al., 2016) and aerodynamic effects of trees on pollutant concentration in street canyons (Buccolieri et al., 2009; Gromke et al., 2008).

In future work, to enhance the performance of the index, it would be necessary to periodically revise risk maps due to the possible replacement of some trees by others and due to the changes provoked by the mortality of some individuals. On the other hand, note that the immature specimens of today will grow and will release more pollen in the near future. In addition, it would be advisable to introduce pruning, and for this, it would be necessary that city councils and urban planning managers were more engaged in all of the procedures. Urban construction guides (Alvarado et al., 2014; MOPT, 1992) could be improved if ornamental tree pruning was considered to manage the air quality. In our case, unsuccessful attempts have been made to work on pruning plane trees, but sometimes the lack of information about local pruning management companies, the different way of working of each professional in each city and a lack of time have not made it possible (Guilherme et al., 2018; Ponchia et al., 2010). This topic is a future challenge and an opportunity to enhance the mapping and to increase the efficiency as an "avoidance risks tool".

This study considered an urban green element (plane tree) as an element to analyse urban sustainability management and improve human health and well-being (Chou et al., 2016; Salmond et al., 2016). It is necessary to integrate the services that the ecosystems provide in landscape planning in order to achieve one of the Sustainable Development Goals (11-sustainable cities and communities) (UNDP, 2019). Furthermore, this methodology could be developed in other cities to promote new results that allow for more comparisons. It will enable us to gain knowledge to establish actual healthy itineraries with minimum exposure to allergenic pollen grains and to design new urban projects that incorporate topological criteria and optimization methods into urban planning (Ekkel and de Vries, 2017; Hilal et al., 2018). This work would be even more beneficial if the last point of the guide focused on a new culture to develop sustainable urban mobility on foot or by bicycle with the objective to provide long-term benefits (Comission-Mobility, 2017) is considered. This new situation would directly increase the exposure of the population to urban green infrastructures. Thus, it is necessary to know the urban natural risk zones, in line with the corrective measures to reduce the impact of urban pollen emissions, including the implementation of nature-based solutions at various levels such as planning and design, handling and management, and strengthening urban green-infrastructure elements (Cariñanos et al., 2017).

\section{Conclusions}

In this work, a new aerobiological index is proposed, the Aerobiological Index of Risk for Ornamental Trees (AIROT). AIROT is a new tool to assist in urban planning and the assessment of potential allergenicity for urban green infrastructures. For this first study case, the risk of exposure to plane tree pollen in cities within a region (Extremadura) in SW Europe is evaluated as an example to be applied in any urban environment. The AIROT index was shown to be a useful tool to map possible biological risks in cities, considering some variables whose role in aerobiological analysis is unclear, such as the effect of slopes and other geographical features, and the barriers consisting of buildings, in the pollen dispersion process. The proposal of a new aerobiological index considering geographical specifications by engineering techniques of remote sensing (LiDAR) and geostatistics (Kriging) provides a new tool for urban planning. AIROT shows the novelty of allowing the study of each city with consideration of their own characteristics. Moreover, the establishment of risk maps and healthy itineraries (or comfortable areas) can be valuable for allergic patients, allergists, architects and urban planners in order to evaluate the potential allergenicity of urban green infrastructure and to design mitigation actions.

\section{Acknowledgements}

This work was made possible by research projects PRI06A190, PRI BS10008, IB16029, research groups aid GR18113 financed by the Regional Government, Junta de Extremadura (Spain), the European Regional Development Fund, and the Irish Environmental Protection Agency (EPA), by means of a Research Fellowship (programme 20142020, Climate, 2017) for JMMM.

\section{Appendix A. Supplementary data}

Supplementary data to this article can be found online at https://doi. org/10.1016/j.scitotenv.2019.07.382.

\section{References}

AEMET, 2018. Climate Statistics. Badajoz Airport (1981-2010). Agencia Estatal de Meteorología, Gobierno de España. Retrieved from www.aemet.es.

Alba, F., Nieto-Lugilde, D., Comtois, P., De La Guardia, C.D., De Linares, C., Ruiz, L., 2006 Airborne-pollen map for Olea europaea L. in eastern Andalusia (Spain) using GIS: estimation models. Aerobiologia 22, 109-118. https://doi.org/https://doi.org 10.1007/s10453-006-9024-0.

Alonzo, M., Bookhagen, B., Roberts, D.A., 2014. Urban tree species mapping using hyperspectral and lidar data fusion. Remote Sens. Environ. 148, 70-83. https://doi org/10.1016/j.rse.2014.03.018.

Alvarado, A., Guajardo, F., Devia, S., 2014. Plantation of Trees in Urban Areas Guide. vol. 94

Barima, Y.S.S., Angaman, D.M., N'Gouran, K.P., Koffi, N.A., Kardel, F., De Cannière, C., Samson, R., 2014. Assessing atmospheric particulate matter distribution based on saturation isothermal remanent magnetization of herbaceous and tree leaves in a tropical urban environment. Sci. Total Environ. 470-471, 975-982. https://doi.org/ https://doi.org/10.1016/j.scitotenv.2013.10.082.

Barnett, J., 2008. Great streets. Planning 74, 16-17.

Bartie, P., Reitsma, F., Kingham, S., Mills, S., 2011. Incorporating vegetation into visual exposure modelling in urban environments. Int. J. Geogr. Inf. Sci. 25, 851-868. https://doi.org/10.1080/13658816.2010.512273.

Bayer, D., Reischl, A., Rötzer, T., Pretzsch, H., 2018. Structural response of black locust (Robinia pseudoacacia L.) and small-leaved lime (Tilia cordata Mill.) to varying urban environments analyzed by terrestrial laser scanning: implications for ecological functions and services. Urban Forestry and Urban Greening 35, 129-138. https://doi.org/10.1016/j.ufug.2018.08.011.

Berens, A.S., Diem, J., Stauber, C., Dai, D., Foster, S., Rothenberg, R., 2017. The use of gammasurvey measurements to better understand radon potential in urban areas. Sci. Total Environ. 607-608, 888-899. https://doi.org/10.1016/j.scitotenv.2017.07.022.

Blanusa, T., Fantozzi, F., Monaci, F., Bargagli, R., 2015. Leaf trapping and retention of particles by holm oak and other common tree species in Mediterranean urban environments. Urban Forestry and Urban Greening 14, 1095-1101. https://doi.org/ 10.1016/j.ufug.2015.10.004.

Blue Marble Geographics, 2016. Global Mapper 16. Retrieved from https://www bluemarblegeo.com/products/global-mapper.php.

Bricchi, E., Frenguelli, G., Mincigrucci, G., 2000. Experimental results about Platanus pollen deposition. Aerobiologia 16 (3-4), 347-352.

Buccolieri, R., Gromke, C., Di Sabatino, S., Ruck, B., 2009. Aerodynamic effects of trees on pollutant concentration in street canyons. Sci. Total Environ. 407, 5247-5256. https://doi.org/10.1016/j.scitotenv.2009.06.016.

Cariñanos, P., Casares-Porcel, M., 2011. Urban green zones and related pollen allergy: a review. Some guidelines for designing spaces with low allergy impact. Landsc. Urban Plan. 101, 205-214. https://doi.org/10.1016/j.landurbplan.2011.03.006.

Cariñanos, P., Alcázar, P., Galán, C., Domínguez, E., 2002. Privet pollen (Ligustrum sp.) as potential cause of pollinosis in the city of Cordoba, south-west Spain. Allergy 57, 92-97. https://doi.org/10.1034/j.1398-9995.2002.103261.x.

Cariñanos, P., Casares-Porcel, M., Quesada-Rubio, J.M., 2014. Estimating the allergenic potential of urban green spaces: a case-study in Granada, Spain. Landsc. Urban Plan. 123, 134-144. https://doi.org/10.1016/j.landurbplan.2013.12.009.

Cariñanos, P., Casares-Porcel, M., Díaz de la Guardia, C., Aira, M.J., Belmonte, J., Boi, M., Elvira-Rendueles, B., De Linares, C., Fernández-Rodriguez, S., Maya-Manzano, J.M. Pérez-Badía, R., Rodriguez-de la Cruz, D., Rodríguez-Rajo, F.J., Rojo-Úbeda, J., Romero-Zarco, C., Sánchez-Reyes, E., Sánchez-Sánchez, J., Tormo-Molina, R., Vega Maray, A.M., 2017. Assessing allergenicity in urban parks: a nature-based solution to reduce the impact on public health. Environ. Res. 155, 219-227. https://doi.org 10.1016/j.envres.2017.02.015.

Caynes, R.J.C., Mitchell, M.G.E., Wu, D.S., Johansen, K., Rhodes, J.R., 2016. Using highresolution LiDAR data to quantify the three-dimensional structure of vegetation in urban green space. Urban Ecosyst. 19, 1749-1765. https://doi.org/10.1007/ s11252-016-0571-z.

Chen, G., Ozelkan, E., Singh, K.K., Zhou, J., Brown, M.R., Meentemeyer, R.K., 2017. Uncertainties in mapping forest carbon in urban ecosystems. J. Environ. Manag. 187, 229-238. https://doi.org/10.1016/j.jenvman.2016.11.062. 
Chou, W.Y., Lee, C.H., Chang, C.Y., 2016. Relationships between urban open spaces and humans' health benefits from an ecological perspective: a study in an urban campus. Landsc. Ecol. Eng. 12, 255-267. https://doi.org/10.1007/s11355-016-0295-5.

Comission-Mobility, E., 2017. General Directorate of Mobility and Transport Investment, Innovation and Sustainability Directorate. Retrieved from https://pagina. jccm.es/europa/pdf/PUBLICACIONES/2017\%20Movilidad\%20Urbana\%20Sostenible. pdf MI-02-16-275-ES-N 40.

Coutts, C., 2016. Green Infrastructure and Public Health. Routledge (ISBN-10: 0415711363. 326 pages)

Della Valle, C.T., Triche, E.W., Bell, M.L., 2012. Spatial and temporal modeling of daily pollen concentrations. Int. J. Biometeorol. 56, 183-194. https://doi.org/10.1007/ s00484-011-0412-y.

Dian, Y., Pang, Y., Dong, Y., Li, Z., 2016. Urban tree species mapping using airborne LiDAR and hyperspectral data. Journal of the Indian Society of Remote Sensing 44, 595-603. https://doi.org/10.1007/s12524-015-0543-4.

Dindaroğlu, T., 2014. The use of the GIS Kriging technnique to determine the spatia changes of natural radionuclide concentrations in soil and forest cover. Journal Environmental Health Science \& Engineering 12, 130. https://doi.org/10.1186/ s40201-014-0130-6.

Duinker, P.N., Ordóñez, C., Steenberg, J.W.N., Miller, K.H., Toni, S.A., Nitoslawski, S.A 2015. Trees in Canadian cities: indispensable life form for urban sustainability. Sustainability (Switzerland) 7, 7379-7396. https://doi.org/10.3390/su7067379.

Ekkel, E.D., de Vries, S., 2017. Nearby green space and human health: evaluating accessibility metrics. Landsc. Urban Plan. 157, 214-220. https://doi.org/10.1016/j. landurbplan.2016.06.008.

Fayad, I., Baghdadi, N., Bailly, J.S., Barbier, N., Gond, V., Hérault, B., Hajj, M.E., Lochard, J., Perrin, J., 2015. Regional scale rain-forest height mapping using regression-kriging of spaceborne and airborne LiDAR data: application on French Guiana. 2015 IEEE International Geoscience and Remote Sensing Symposium (IGARSS) 4109-4112. https://doi.org/10.1109/IGARSS.2015.7326729.

Fernández-González, M., Guedes, A., Abreu, I., Rodríguez-Rajo, F.J., 2013. Pla a_1 aeroallergen immunodetection related to the airborne Platanus pollen content. Sci. Total Environ. 463-464, 855-860. https://doi.org/10.1016/j.scitotenv.2013.06.062.

Fernández-González, M., Rodríguez-Rajo, J., Escuredo, O., Aira, M.J., 2013. Optimization of integrated pest management for powdery mildew (Unincula necator) control in a vineyard based on a combination of phenological, meteorological and aerobiological data. J Agric. Sci. 151, 648-658. https://doi.org/10.1017/S0021859612000743.

Fernández-Rodríguez, S., Maya-Manzano, J.M., I., S.-P., Gonzalo-Garijo, A., TormoMolina, R., 2013. Relación entre la abundancia y distribución de plátanos de sombra en el muestreo polínico en altura y distancia (relationship between the abundance and distribution of plane trees in the pollen sampling in heigh and distance). Revista Salud Ambiental 13, 152-322.

Fernández-Rodríguez, S., Tormo-Molina, R., Maya-Manzano, J.M., Silva-Palacios, I., Gonzalo-Garijo, A., 2014. Comparative study of the effect of distance on the daily and hourly pollen counts in a city in the south-western Iberian Peninsula. Aerobiologia 30, 173-187. https://doi.org/10.1007/s10453-013-9316-0.

Fernández-Rodríguez, S., Skjøth, C.A., Tormo-Molina, R., Brandao, R., Caeiro, E., SilvaPalacios, I., Gonzalo-Garijo, A., Smith, M., 2014b. Identification of potential sources of airborne Olea pollen in the Southwest Iberian Peninsula. Int. J. Biometeorol. 58 337-348. https://doi: https://doi.org/10.1007/s00484-012-0629-4.

Fernández-Rodríguez, S., Cortés-Pérez, J.P., Muriel, P.P., Tormo-Molina, R. Maya-Manzano, J.M., 2018. Environmental impact assessment of Pinaceae airborne pollen and green infrastructure using BIM. Autom. Constr. 96, 494-507. https://doi. org/10.1016/j.autcon.201810.011.

Gamba, P., Houshmand, B., 2000. Digital surface models and building extraction: comparison of IFSAR and LIDAR data. IEEE Trans. Geosci. Remote Sens. 38, 19591968. https://doi.org/10.1109/36.851777.

Gavier-Pizarro, G.I., Kuemmerle, T., Hoyos, L.E., Stewart, S.I., Huebner, C.D., Keuler, N.S. Radeloff, V.C., 2012. Monitoring the invasion of an exotic tree (Ligustrum lucidum) from 1983 to 2006 with Landsat TM/ETM+ satellite data and support vector Machines in Córdoba, Argentina. Remote Sens. Environ. 122, 134-145. https://doi. org/10.1016/j.rse.2011.09.023.

Gehrig, R., Peeters, A.G., 2000. Pollen distribution at elevations above $1000 \mathrm{~m}$ in Switzerland. Aerobiologia 16 (1), 69-74. https://doi.org/10.1023/A:1007607121614.

Germino, M.J., Smith, W.K., Resor, A.C., 2002. Conifer seedling distribution and survival in an alpine-treeline ecotone. Plant Ecol. 162, 157-168. https://doi.org/https://doi. org/10.1023/A:1020385320738.

Gillespie, T.W., de Goede, J., Aguilar, L., Jenerette, D.E., Fricker, G.A., Avolio, M.L., Pincetl, S. Johnston, T., Clarke, L.W., Pataki, D.E., 2016. Predicting tree species richness in urban forests. Urban Ecosyst. 1-11. https://doi.org/10.1007/s11252-016-0633-2.

Golan, A., 2015. The street as urban icon? Tel Avivs Rothschild Boulevard. Urban Geogr 36, 721-734. https://doi.org/10.1080/02723638.2015.1016308.

Gromke, C., Buccolieri, R., Di Sabatino, S., Ruck, B., 2008. Dispersion study in a street canyon with tree planting by means of wind tunnel and numerical investigations - evaluation of CFD data with experimental data. Atmos. Environ. 42, 8640-8650. https://doi.org/10.1016/j.atmosenv.2008.08.019.

Guilherme, F.A.G., Silva, M.C., Carneiro, D.N.M., Nascimento, H.C.A., Ressel, K. Ferreira, W.C., 2018. Urban arborization in public pathways of four cities in eas Mato Grosso do Sul (MS) Brazil. Ornamental Horticulture 24, 174-181. http://dx. doi.org/10.14295/oh.v24i2.1137.

Hilal, M., Joly, D., Roy, D., Vuidel, G., 2018. Visual structure of landscapes seen from built environment. Urban Forestry and Urban Greening 32, 71-80. https://doi.org/ 10.1016/j.ufug.2018.03.020

Hoekstra, M.J., 2012. The plan Zuid in words: changing notions in urbanism and an unknown plan. KNOB Bulletin 111, 186-198. https://doi.org/10.7480 knob.111.2012.4.353.
IGN, 2019. CORINE Land Cover. Instituto Geográfico Nacional del Gobieno de España. Retrieved from http://www.ign.es/ign/main/index.do.

Imai, Y, Setojima, M., Yamagishi, Y., Fujiwara, N., 2004. Tree-height measuring characteristics of urban forests by LIDAR data different in resolution. International Archives of the Photogrammetry, Remote Sensing and Spatial Information Sciences - ISPRS Archives, pp. 513-516. Retrieved from http://www.isprs.org/proceedings/ xxxv/congress/comm7/papers/100.pdf.

Jenerette, G.D., Harlan, S.L., Buyantuev, A., Stefanov, W.L., Declet-Barreto, J., Ruddell, B.L., Myint, S.W., Kaplan, S., Li, X., 2016. Micro-scale urban surface temperatures are related to land-cover features and residential heat related health impacts in Phoenix, AZ USA Landsc. Ecol. 31, 745-760. https://doi.org/10.1007/s10980-015-0284-3.

Johnson, L.E., Bishop, T.F.A., Birch, G.F., 2017. Modelling drivers and distribution of lead and zinc concentrations in soils of an urban catchment (Sydney estuary, Australia). Sci. Total Environ. 598, 168-178. https://doi.org/10.1016/j.scitotenv.2017.04.033.

Kjelgren, R.K., Clark, J.R., 1992. Microclimates and tree growth in three urban spaces. J, Environ. Hortic. 10 (3), 139-145.

León Ruiz, E.J., García Mozo, H., Domínguez Vilches, E., Galán, C., 2012. The use of geostatistics in the study of floral phenology of Vulpia geniculata (L.) link. TheScientificWorldJournal 2012, 624247. https://doi.org/10.1100/2012/624247.

León-Ruiz, E., Alcázar, P., Domínguez-Vilches, E., Galán, C., 2011. Study of Poaceae phenology in a Mediterranean climate. Which species contribute most to airborne pollen counts? Aerobiologia 27, 37-50. https://doi.org/10.1007/s10453-010-9174-y.

Lin, Y., West, G., 2016. Reflecting conifer phenology using mobile terrestrial LiDAR: a case study of Pinus sylvestris growing under the Mediterranean climate in Perth, Australia. Ecol. Indic. 70, 1-9. https://doi.org/10.1016/j.ecolind.2016.06.003.

Lovasi, G.S., O'Neil-Dunne, J.P.M., Lu, J.W.T., Sheehan, D., Perzanowski, M.S., Macfaden, S.W., King, K.L., Matte, T., Miller, R.L., Hoepner, L.A., Perera, F.P., Rundle, A., 2013. Urban tree canopy and asthma, wheeze, rhinitis, and allergic sensitization to tree pollen in a New York city birth cohort. Environ. Health Perspect. 121, 494-500. https://doi.org/10.1289/ehp.1205513.

Luo, S., Wang, C., Xi, X., Pan, F., Peng, D., Zou, J., Nie, S., Qin, H., 2017. Fusion of airborne LiDAR data and hyperspectral imagery for aboveground and belowground forest biomass estimation. Ecol. Indic. 73, 378-387. https://doi.org/10.1016/j.ecolind.2016.10.001.

Machida, L., Derera, J., Tongoona, P., Mutanga, O., MacRobert, J., 2012. Geostatistical analysis of quality protein maize outcrossing with pollen from adjacent normal endosperm maize varieties. Crop Sci. 52, 1235-1245. https://doi.org/10.2135/ cropsci2011.08.0448.

Maheshwari, B.L., Plunkett, M., 2015. Best practice irrigation management and extension in Peri-urban landscapes - experiences and insights from the Hawkesbury-Nepean catchment, Australia. J. Agric. Educ. Ext. 21, 267-282. https://doi.org/ 10.1080/1389224X.2014.927376.

Maimaitiyiming, M., Ghulam, A., Tiyip, T., Pla, F., Latorre-Carmona, P., Halik, T., Sawut, M., Caetano, M., 2014. Effects of green space spatial pattern on land surface temperature: implications for sustainable urban planning and climate change adaptation. ISPRS J. Photogramm. Remote Sens. 89, 59-66. https://doi.org/https://doi. org/10.1016/j.isprsjprs.2013.12.010.

Massetti, L., Petralli, M., Orlandini, S., 2015. The effect of urban morphology on Tiliax europaea flowering. Urban Forestry and Urban Greening 14, 187-193. https:// doi.org/10.1016/j.ufug.2014.10.005.

Matějíček, L., Engst, P., Jaňour, Z., 2006. A GIS-based approach to spatio-temporal analysis of environmental pollution in urban areas: a case study of Prague's environment extended by LIDAR data. Ecol. Model. 199, 261-277. https://doi.org/10.1016/ j.ecolmodel.2006.05.018.

Maya-Manzano, J.M., Fernández-Rodríguez, S., Monroy-Colín, A., Silva-Palacios, I., Tormo-Molina, R., Gonzalo-Garijo, Á., 2017. Allergenic pollen of ornamental plane trees in a Mediterranean environment and urban planning as a prevention tool. Urban Forestry and Urban Greening 27, 352-362. https://doi.org/10.1016/j.ufug.2017.09.009.

Maya-Manzano, J.M., Sadyś, M., Tormo-Molina, R., Fernández-Rodríguez, S., Oteros, J., Silva-Palacios, I., Gonzalo-Garijo, A., 2017. Relationships between airborne pollen grains, wind direction and land cover using GIS and circular statistics. Sci. Total Environ. 584-585, 603-613. https://doi.org/10.1016/j.scitotenv.2017.01.085.

Maya-Manzano, J.M. Tormo-Molina, R. Fernández-Rodríguez, S., Silva-Palacios, I. Gonzalo-Garijo, Á., 2017. Distribution of ornamental urban trees and their influence on airborne pollen. Landsc. Urban Plan. 157, 434-446. https://doi.org/ 10.1016/j.landurbplan.2016.08.011.

MOPT, 1992. Ministerio de Obras Públicas y Transportes. Manual de plantación en el entorno de la carretera. Retrieved from http://www.fomento.es/NR/rdonlyres/ 4FABE603-6468-4A82-B4C7-D2D0F5F01355/55708/1310100.pdf.

Mrđan, S., Ljubojević, M., Orlović, S., Čukanović, J., Dulić, J., 2017. Poisonous and allergenic plant species in preschool's and primary school's yards in the city of Novi Sad. Urban Forestry and Urban Greening 25, 112-119. https://doi.org/10.1016/j. ufug.2017.05.007.

Mueller, N., Rojas-Rueda, D., Khreis, H., Cirach, M., Milà, C., Espinosa, A., Foraster, M., McEachan, R.R.C., Kelly, B., Wright, J., Nieuwenhuijsen, M., 2018. Socioeconomic inequalities in urban and transport planning related exposures and mortality: a health impact assessment study for Bradford, UK. Environ. Int. 121, 931-941. https://doi.org/10.1016/j.envint.2018.10.017.

Murgoitio, J.J., Shrestha, R., Glenn, N.F., Spaete, L.P., 2013. Improved visibility calculations with tree trunk obstruction modeling from aerial LiDAR. Int. J. Geogr. Inf. Sci. 27. 1865-1883. https://doi.org/10.1080/13658816.2013.767460.

Noh, Y.M., Lee, H., Mueller, D., Lee, K., Shin, D., Shin, S., Choi, T.J., Choi, Y.J., Kim, K.R., 2013. Investigation of the diurnal pattern of the vertical distribution of pollen in the lower troposphere using LIDAR. Atmos. Chem. Phys. 13, 7619-7629. https:// doi.org/10.5194/acp-13-7619-2013.

NSI, 2017. Population by Cities. National Institute of Statistics, Madrid, Spain. Retrieved from https://www.ine.es/. 
Oteros, J., Bergmann, K.-C., Menzel, A., Damialis, A., Traidl-Hoffmann, C., Schmidt-Weber, C., Buters, J., 2019. Spatial interpolation of current airborne pollen concentrations where no monitoring exists. Atmos. Environ. 199, 435-442. https://doi.org/10.1016/j.atmosenv.2018.11.045.

Parmehr, E.G., Amati, M., Taylor, E.J., Livesley, S.J., 2016. Estimation of urban tree canopy cover using random point sampling and remote sensing methods. Urban Forestry and Urban Greening 20, 160-171. https://doi.org/10.1016/j.ufug.2016.08.011.

Plowright, A.A., Coops, N.C., Eskelson, B.N.I., Sheppard, S.R.J., Aven, N.W., 2016. Assessing urban tree condition using airborne light detection and ranging. Urban Forestry and Urban Greening 19, 140-150. https://doi.org/10.1016/j.ufug.2016.06.026.

Ponchia, G., Simeoni, S., Zanin, G., 2010. Influence of winter pruning on ornamental plants grown in two kinds of container. Acta Hortic. 581-584. https://doi.org/ 10.17660/ActaHortic.2010.881.97.

Puppi Branzi, G., Zanotti, L.Z., 1992. Estimate and mapping of the activity of airborne pollen sources. Aerobiologia 8, 69-74. https://doi.org/https://doi.org/10.1007/ BF02291332.

Puppi, G., Zanotti, A.L., 1989. Methods in Phenological mapping. Aerobiologia 5, 44-54. https://doi.org/10.1007/BF02446487.

Ríos, B., Torres-Jardón, R., Ramírez-Arriaga, E., Martínez-Bernal, A., Rosas, I., 2016. Diurnal variations of airborne pollen concentration and the effect of ambient temperature in three sites of Mexico City. Int. J. Biometeorol. 60, 771-787. https://doi.org/ 10.1007/s00484-015-1061-3.

Rohde, R.A., Muller, R.A., 2015. Air pollution in China: mapping of concentrations and sources. PLoS One 10. https://doi.org/10.1371/journal.pone.0135749.

Rojo, J., Pérez-Badia, R., 2015. Spatiotemporal analysis of olive flowering using geostatistical techniques. Sci. Total Environ. 505, 860-869. https://doi.org/10.1016/j.scitotenv.2014.10.022.

Rojo, J., Rapp, A., Lara, B., Fernández-González, F., Pérez-Badia, R., 2015. Effect of land uses and wind direction on the contribution of local sources to airborne pollen. Sci. Total Environ. 538, 672-682. https://doi.org/10.1016/j.scitotenv.2015.08.074.

R-Team, C, 2013. R Core Team. 2013. R: A Language and Environment for Statistical Computing. R Foundation for Statistical Computing, Vienna, Austria. http://www. R-project.org.

Salmond, JA, Tadaki, M., Vardoulakis, S, Arbuthnott, K, Coutts, A., Demuzere, M. Dirks, K.N., Heaviside, C., Lim, S., MacIntyre, H., McInnes, R.N., Wheeler, B.W., 2016. Health and climate related ecosystem services provided by street trees in the urban environment. Environmental Health: A Global Access Science Source 15. https://doi.org/10.1186/s12940-016-0103-6.

Scheifinger, H., Menzel, A., Koch, E., Peter, Ch, Ahas, R., 2002. Atmospheric mechanisms governing the spatial and temporal variability of phenological observations in central Europe. Int. J. Climatol. 22, 1739-1755.

Senes, G., Fumagalli, N., Ferrario, P.S., Gariboldi, D., Rovelli, R., 2016. Municipal community gardens in the metropolitan area of Milano. Assessment and planning criteria. Journal of Agricultural Engineering 47, 82-87. https://doi.org/10.4081/jae.2016.509.

Sharma, C.M., Khanduri, V.P., Ghildiyal, S.K., 2012. Reproductive ecology of male and female strobili and mating system in two different populations of Pinus roxburghii. Sci. World J. 2012. https://doi.org/10.1100/2012/271389.

Sicard, M., Izquierdo, R., Alarcón, M., Belmonte, J., Comerón, A., Baldasano, J.M., 2016. Near-surface and columnar measurements with a micro pulse lidar of atmospheric pollen in Barcelona, Spain. Atmos. Chem. Phys. 16, 6805-6821. https://doi.org/ 10.5194/acp-16-6805-2016.
Sicard, P., Serra, R., Rossello, P., 2016. Spatiotemporal trends in ground-level ozone concentrations and metrics in France over the time period 1999-2012. Environ. Res. 149, 122-144. https://doi.org/10.1016/j.envres.2016.05.014.

Silva-Palacios, I., Tormo-Molina, R., Muñoz-Rodríguez, A., 2000. Influence of wind direction on pollen concentration in the atmosphere. Int. J. Biometeorol. 44, 128-133.

Skjøth, C.A., Ørby, P.V., Becker, T., Geels, C., Schlünssen, V., Sigsgaard, T., Bønløkke, J.H Sommer, J., Søgaard, P., Hertel, O., 2013. Identifying urban sources as cause of elevated grass pollen concentrations using GIS and remote sensing. Biogeosciences 10, 541-554. https://doi.org/10.5194/bg-10-541-2013.

Smith, M., Skjoth, C.A., Myszkowska, D., Uruska, A., Puc, M., Stach, A., Balwierz, Z., Chlopek, K., Piotrowska, K., Kasprzyk, I., Brandt, J., 2008. Long-range transport of Ambrosia pollen to Poland. Agric. For. Meteorol. 148, 1402-1411. https://doi.org/ 10.1016/j.agrformet.2008.04.005.

Sreelekha, M.G., Krishnamurthy, K., Anjaneyulu, M.V.L.R., 2017. Fractal Assessment of Road Transport System. European Transport - Trasporti Europei. Retrieved from http://www.istiee.org/te/papers/N65/P05_65_08_2017.pdf.

Staffolani, L., Velasco-Jiménez, M.J., Galán, C., Hruska, K., 2011. Allergenicity of the ornamental urban flora: ecological and aerobiological analyses in Córdoba (Spain) and Ascoli Piceno (Italy). Aerobiologia 27, 239-246. https://doi.org/10.1007/ s10453-010-9193-8.

Steiner, F., 2011. Landscape ecological urbanism: origins and trajectories. Landsc. Urban Plan. 100, 333-337. https://doi.org/10.1016/j.landurbplan.2011.01.020.

Tang, L., Wang, L., Li, Q., Zhao, J., 2018. A framework designation for the assessment of urban ecological risks. Int J Sust Dev World 25, 387-395. https://doi.org/10.1080/ 13504509.2018.1434570.

Thomas, S.C., Winner, W.E., 2002. Photosynthetic differences between saplings and adult trees: an integration of field results by meta-analysis. Tree Physiol. 22, 117127. https://doi.org/10.1093/treephys/22.2-3.117.

Thompson, R.S., 1993. Building amplification factors for sources near buildings: a windtunnel study. Atmos. Environ. Part A 27, 2313-2325. https://doi.org/10.1016/ 0960-1686(93)90400-S.

Tong, Z., Baldauf, R.W., Isakov, V., Deshmukh, P., Max Zhang, K., 2016. Roadside vegetation barrier designs to mitigate near-road air pollution impacts. Sci. Total Environ. 541, 920-927. https://doi.org/10.1016/j.scitotenv.2015.09.067.

Tormo-Molina, R., Muñoz-Rodríguez, A., Silva-Palacios, I., Gallardo-López, F., 1996 Pollen production in anemophilous trees. Grana 35, 38-46. https://doi.org/ $10.1080 / 00173139609430499$.

Tsui, O.W., Coops, N.C., Wulder, M.A., Marshall, P.L., 2013. Integrating airborne LiDAR and space-borne radar via multivariate kriging to estimate above-ground biomass. Remote Sens. Environ. 139, 340-352. https://doi.org/10.1016/j.rse.2013.08.012.

UNDP, 2019. United Nations Development Programme. Sustainable Development Goals. Retrieved from http://www.undp.org/content/undp/en/home/sustainabledevelopment-goals.html.

Vaz Monteiro, M., Levanič, T., Doick, K.J., 2017. Growth rates of common urban trees in five cities in Great Britain: a dendrochronological evaluation with an emphasis on the impact of climate. Urban Forestry and Urban Greening 22, 11-23. https://doi. org/10.1016/j.ufug.2017.01.003.

Velasco-Jiménez, M.J., Alcázar, P., Valle, A., Trigo, M.M., Minero, F., Domínguez-Vilches, E., Galán, C., 2014. Aerobiological and ecological study of the potentially allergenic ornamental plants in South Spain. Aerobiologia 30, 91-101. https://doi.org/10.1007/s10453-013-9311-5. 